DOI: http://dx.doi.org/10.18185/eufbed.74815

EÜFBED - Fen Bilimleri Enstitüsü Dergisi Cilt-Sayı: 8-2 Yıl: 2015 248-258

\title{
A NEW INSTABILITY RESULT ON THE SOLUTIONS OF NONLINEAR VECTOR DIFFERENTIAL EQUATIONS OF THE FIFTH ORDER
}

\section{BEŞINCI MERTEBEDEN LINEER OLMAYAN VEKTÖR DIFERENSIYEL DENKLEMLERINN ÇÖZÜMLERININN KARARSIZLIĞI ÜZERINE YENİ BİR SONUÇ}

\author{
Melike KARTA ${ }^{*}$ \\ 1Department of Mathematics, Faculty of Science and Arts, A $\breve{g r}$ \\ İbrahim Çeçen University, A ̆grl, Turkey
}

Geliş Tarihi (Received): 06/04/2015 Kabul Tarihi (Accepted): 27/07/2015

\section{ABSTRACT}

In this paper, it is considered the following fifth order dfferential system:

$X^{(5)}+A X^{(4)}+\Theta\left(X, \dot{X}, \ddot{X}, \dddot{X}, X^{(4)}\right) \dddot{X}+F(\dot{X}) \ddot{X}$

$+G\left(X, \dot{X}, \ddot{X}, \dddot{X}, X^{(4)}\right) \dot{X}+H(X)=0$

in the real Euclidean space $\mathbb{R}$.

Sufficient conditions and an example are given for the instability of the zero solution to the considered equation. Based on the Krasovskii criteria and Lyapunov's second method, a theorem is proved on the subject.

Keywords: Instability, Krasovskii criteria, Lyapunov's second method, Nonlinear differential equations of fifth order.

ÖZET

Bu makalede, $\mathbb{R}$ reel öklid uzayında

$X^{(5)}+A X^{(4)}+\Theta\left(X, \dot{X}, \ddot{X}, \dddot{X}, X^{(4)}\right) \dddot{X}+F(\dot{X}) \ddot{X}$

$+G\left(X, \dot{X}, \ddot{X}, \dddot{X}, X^{(4)}\right) \dot{X}+H(X)=0$

beşinci mertebeden diferensiyel denklemi düşünülür. Düşünülen denklemin sıfır çözümünün kararsızlığı için yeter şartlar ve bir örnek verilir. krasovskii kriteri ve Lyapunov'un ikinci metodunu esas alarak, konu ile ilgili bir teorem ispatlanir.

Anahtar Kelimeler: Kararsızlık, Krasovskii kriteri, Lyapunov'un ikinci metodu, Beşinci mertebe lineer olmayan diferensiyel denklemler.

*Sorumlu Yazar: melike_karta2010@hotmail.com 
Karta

\section{INTRODUCTION}

Stability and instability of the solution in practice and theory of scalar and vector differential equations has a very important place. For this, some methods have been developed related explanations behavior of the solution. The best known of these methods is Lyapunov's the second method.

High order scalar and vector differential equations have emerged in the applied sciences as some practical mechanical problems, physics, chemistry, biology, ecomomics, control theory.

Instability of the trivial solution of scalar and vector differential equations of the fifth order were investigated by many authors. About the topic, we refer to the papers of (Ezeilo 1978, 1979), (Tiryaki 1987), (Li \& Yu 1990), (Li \& Duan 2000), (Sadek 2003), (Tunç 2004, 2005), (Tunç \& Şevli 2008), (Tunç \& Karta 2008), (Krasovskii 1955). In all of the papers mentioned above, authors used Krasovskii's criteria (1955) and Lyapunov's second (or direct) method (1966).

Now, we give these studies that were done on the instability of non-linear differential equations of the fifth order. According to observations in the literature, firstly, for the case $n=1$, Ezeilo (1978, 1979) investigated the instability of trivial solution of the fifth order scalar non-linear differential equations, respectively,

$x^{(5)}+a_{1} x^{(4)}+a_{2} \dddot{x}+a_{3} \ddot{x}+a_{4} \dot{x}+f(x)=0$,

$x^{(5)}+a_{1} x^{(4)}+a_{2} \dddot{x}+h(\dot{x}) \ddot{x}+g(x) \dot{x}+f(x)=0$,

$x^{(5)}+\psi(\ddot{x}) \ddot{x}+\varphi(\ddot{x})+\theta(\dot{x})+f(x)=0$

and

$x^{(5)}+a_{1} x^{(4)}+a_{2} \dddot{x}+g(\dot{x}) \ddot{x}+h\left(x, \dot{x}, \ddot{x}, \dddot{x}, x^{(4)}\right) \dot{x}+f(x)=0$,

in which $a_{1}, a_{2}, a_{3}, a_{4}$ are constants and $f, g, h, \psi, \phi$ and $\theta$ are continuous functions depending only on the arguments shown as $f(0)=\phi(0)=\theta(0)=0$.

(Tiryaki 1987) studied the instability of trivial solution of the fifth order non-linear scalar differential equation of the form

EÜFBED - Fen Bilimleri Enstitüsü Dergisi Cilt-Sayı: 8-2 Yıl: 2015 248-258 
$\frac{\text { A New Instability Result on The Solutions of Nonlinear Vector }}{x^{(5)}+a_{1} x^{(4)}+k\left(x, \dot{x}, \ddot{x}, \dddot{x}, x^{(4)}\right) \dddot{x}+g(\dot{x}) \ddot{x}+h\left(x, \dot{x}, \ddot{x}, \dddot{x}, x^{(4)}\right) \dot{x}+f(x)=0 .}$

(Li \& Yu 1990) concerned the instability of trivial solution of the fifth order non-linear scalar differential equation

$x^{(5)}+a x^{(4)}+b \dddot{x}+\psi\left(x, \dot{x}, \ddot{x}, \dddot{x}, x^{(4)}\right) \ddot{x}+g(x) \dot{x}+f(x)=0$

By introducing a Lyapunov function, where $a$ and $b$ are some positive constant.

(Li \& Duan 2000) showed the instability of trivial solution of the fifth order nonlinear scalar differential equation of the form

$\dot{x}_{i}=x_{i+1} \quad \dot{x}_{i}=x_{i+1} \quad(i=1,2,3,4)$

$\dot{x}_{5}=-f_{5}\left(x_{4}\right) x_{5}-f_{4}\left(x_{3}\right) x_{4}-f_{3}\left(x_{1}, x_{2}, x_{3}, x_{4}, x_{5}\right) x_{3}-f_{2}\left(x_{2}\right)-f_{1}\left(x_{1}\right)$

$$
\left(f_{2}(0)=f_{1}(0)=0\right)
$$

and

$$
\begin{gathered}
\dot{x}_{i}=x_{i+1} \quad \dot{x}_{i}=x_{i+1} \quad(i=1,2,3,4) \\
=-a_{5} x_{5}-f_{4}\left(x_{1}, x_{2}, x_{3}, x_{4}, x_{5}\right) x_{4}-f_{3}\left(x_{2}\right) x_{3}-f_{2}\left(x_{1}, x_{2}, x_{3}, x_{4}, x_{5}\right) x_{2}-f_{1}\left(x_{1}\right)
\end{gathered}
$$

On the other hand, Sadek (2003) examined the instability of trivial solutions of the fifth order vector differential equations described as

$$
X^{(5)}+\Psi(\ddot{X}) \dddot{X}+\Phi(\ddot{X})+\Theta(\dot{X})+F(X)=0
$$

and

$X^{(5)}+A X^{(4)}+B \dddot{X}+H(\dot{X}) \ddot{X}+G(X) \dot{X}+F(X)=0$.

In addition, respectively, (Tunç 2004, 2005) investigated the instability of trivial solution of the fifth order vector differential equations of the form

$$
\begin{aligned}
X^{(5)}+ & A X^{(4)}+\Psi\left(X, \dot{X}, \ddot{X}, \dddot{X}, X^{(4)}\right) \dddot{X}+G(\dot{X}) \ddot{X}+H\left(X, \dot{X}, \ddot{X}, \dddot{X}, X^{(4)}\right) \dot{X}+F(X)=0, \\
X^{(5)} & +A X^{(4)}+B(t) \Psi\left(X, \dot{X}, \ddot{X}, \dddot{X}, X^{(4)}\right) \dddot{X}+C(t) G(\dot{X}) \ddot{X} \\
& +D(t) H\left(X, \dot{X}, \ddot{X}, \dddot{X}, X^{(4)}\right) \dot{X}+E(t) F(X)=0
\end{aligned}
$$

EÜFBED - Fen Bilimleri Enstitüsü Dergisi Cilt-Sayı: 8-2 Yıl: 2015 248-258 
Karta

and

$X^{(5)}+\Psi(\dot{X}, \ddot{X}) \ddot{X}+\Phi\left(\dot{X}, \ddot{X}_{,}, X_{,} X^{(4)}\right)+\Theta(\dot{X})+F(X)=0$.

(Tunç \& Şevli 2008) showed a similar study for the instability of trivial solution of the fifth order vector differential equation

$X^{(5)}+\Psi(\dot{X}, \ddot{X}) \dddot{X}+\Phi(X, \dot{X}, \ddot{X}) \ddot{X}+\theta(\dot{X})+F(X)=0$.

Furthermore, (Tunç \& Karta 2008) analyzed sufficient conditions which ensure the trivial solution of vector differential equation

$X^{(5)}+A X^{(4)}+B \dddot{X}+\Psi\left(X, \dot{X}, \ddot{X}, \dddot{X}, X^{(4)}\right) \ddot{X}+G(X) \dot{X}+F(X) X=0$

By introducing a Lyapunov function, where $A$ and $B$ are constant $n x n-$ symmetric matrices; $\Psi, G$ and $F$ are $n x n-$ symmetric continuous matrix functions depending, in each case, on the arguments shown.

In addition, for some related contributors to the subject, we refer to the papers of (Tunç 2004, 2013). In all of the above mentioned papers, authors took into consideration of Krasovskii 's criteria (1955) and Lapunov's second (or direct) method (1993).

In this article, based on study produced by (Li \& Duan 2000), we investigate the instability of the zero solution of the fifth- order non-linear vector differential equations of the form

$$
\begin{aligned}
& X^{(5)}+A X^{(4)}+\Theta\left(X, \dot{X}, \ddot{X}, \dddot{X}, X^{(4)}\right) \dddot{X}+F(\dot{X}) \ddot{X} \\
& +G\left(X, \dot{X}, \ddot{X}, \dddot{X}, X^{(4)}\right) \dot{X}+H(X)=0
\end{aligned}
$$

in the real Euclidean space $\mathbb{R}^{n}$ (with the usual norm denoted in what follows by $\|$.$\| ),$

in which $X \in \mathbb{R}^{n} ; A$ is constant $n \times n$-symmetric matrix; $\Theta, F$ and $G$ are $n \times n$-symmetric continuous matrix functions depending, in each case, on the arguments shown; $H: \mathbb{R}^{n} \rightarrow \mathbb{R}^{n}$ is continuous $n$-vector function. It is supposed that the function $H$ is continuous and $H(0)=0, H(X) \neq 0$ for $X \neq 0$. Let $J_{H}(X)$ and $I_{F}(Y)$ display the Jacobian matrices corresponding to the functions $H(X)$ and $F(Y)$, respectively, that is,

$J_{H}(X)=\left(\frac{\partial h_{i}}{\partial x_{j}}\right), J_{F}(Y)=\left(\frac{\partial f_{i}}{\partial y_{j}}\right), \quad(\mathrm{i}, j=1,2, \ldots, \mathrm{n})$

EÜFBED - Fen Bilimleri Enstitüsü Dergisi Cilt-Sayl: 8-2 Yıl: 2015 248-258 
A New Instability Result on The Solutions of Nonlinear Vector in which $\left(x_{1}, x_{2}, \ldots, x_{n}\right),\left(y_{1}, y_{2}, \ldots, y_{n}\right),\left(f_{1}, f_{2,}, \ldots, f_{n}\right)$ and $\left(h_{1}, h_{2}, \ldots, h_{n}\right)$, are the components of $X, Y, F$ and $H$, respectively. The symbol $(X, Y\rangle$ corresponding to any pair $X, Y$ in $\mathbb{R}^{n}$ stands for the usual scalar product $\sum_{i=1}^{n} x_{i} y_{i}$, and the matrix $A=\left(a_{i j}\right)$ is said to be positive definite if and only if the quadratic form $X^{T} A X$ is positive definite, where $X \in \mathbb{R}^{n}$ and $X^{T}$ denotes the traspose of $X$.

Throughout this paper, we consider the following differential systems which are equivalent to the equation (1.2) which was attained as usual by setting $\dot{X}=Y, \ddot{X}=Z, \mathbb{X}=W, X^{(4)}=U$ from (1.2):

$\dot{X}=Y, \dot{Y}=Z, \dot{Z}=W, \dot{W}=U$

$\dot{U}=-A U-\Theta(X, Y, Z, W, U) W-F(Y) Z-G(X, Y, Z, W, U) Y-H(X)$

There are a few examples about the subject in the literature and we give an example to indicate the importance of the topic. Also, it should be expressed that the assumptions in the theorem and (Lyapunov 1966) function used here are completely different than those mentioned in the literature.

\section{MAIN RESULT}

Our main result is the following theorem.

Theorem 2.1. In addition to the basic conditions given above for coefficients $A, \Theta, F, G$ and $H$ of (1.2) equation, it is assumed that $A$ and $I_{H}(X)$ are symmetric matrices and there is constant $a_{1}$, a positive constant as the following conditions hold:

(i) $\quad \lambda_{\mathrm{i}}(A)>a_{1},(i=1,2, \ldots, n)$

(ii)

$\lambda_{i}(G(X, Y, Z, W, U))-\frac{1}{4}\left[\lambda_{i}(\Theta(X, Y, Z, W, U))\right]^{2}>0, \quad(i=1,2, \ldots, n)$

Then trivial solution $X=0$ of (1.2) is instability.

Now, in order to prove main result, we use the following lemma.

Lemma2.2. Let $A$ be a real symmetric $n \times n$-matrix and

EÜFBED - Fen Bilimleri Enstitüsü Dergisi Cilt-Sayı: 8-2 Yıl: 2015 248-258 
Karta

$$
a^{2} \geq \lambda_{i}(A) \geq a>0 \quad(i=1,2, \ldots, n),
$$

in which $a^{2}, a$ are constants.

Then

$$
\langle X, X\rangle \geq\langle A X, X\rangle \geq a\langle X, X\rangle, a^{2^{2}}\langle X, X\rangle \geq\langle A X, A X\rangle \geq a^{2}\langle X, X\rangle .
$$

(2.2) See [23] for proof .

Proof. As basic tool for proof of Theorem (2.1), we will use Lyapunov function $V(X, Y, Z, W, U)$ given as

$$
\begin{aligned}
V= & -\langle Y, U\rangle+\langle Z, W\rangle-\langle A Y, W\rangle+\frac{1}{2}\langle A Z, Z\rangle-\int_{0}^{1}\langle F(\sigma Y) Y, Y\rangle d \sigma \\
& -\int_{0}^{1}\langle H(\sigma X), X\rangle d \sigma .
\end{aligned}
$$

under the conditions of Theorem 2.1, it will be indicated that the Lyapunov function $V(X, Y, Z, W, U)$ satisfies the entire (Krasovskii 1955) criteria:

$\left(K_{1}\right)$ In every neighborhood of $(0,0,0,0,0)$, there exists a point $\left(\xi, \eta, \xi_{,}, \rho\right)$ such as $V\left(\xi, \eta, \xi_{,}, \rho\right)>0$.

$\left(K_{2}\right)$ The time derivative $V=\left(\frac{d}{d t}\right) V(X, Y, Z, W, U)$ along solution paths of system (1.3) is positive semidefinite.

$\left(K_{a}\right)$ The only solution $V(X, Y, Z, W, U)=(X(t), Y(t), Z(t), W(t), U(t))$ of system (1.3) which satisfies $V=0(t \geq 0)$ is the trivial solution $(0,0,0,0,0)$. These properties guarantee that the trivial solution of $(1.2)$ is unstable. It is clear from $(2.1)$ that $V_{1}(0,0,0,0,0)=0$. Additionally, it is easy to see that

$$
V(0,0, \varepsilon, \varepsilon, 0)==\|\varepsilon\|^{2}+\frac{1}{2} a_{1}\|\varepsilon\|^{2}>0
$$

for all arbitrary $\varepsilon \neq 0, \varepsilon \in \mathbb{R}^{n}$. If this happens, it displays $\left(K_{1}\right)$ feature of (Krasosvkii 1955). Let $(X, Y, Z, W, U)=(X(t), Y(t), Z(t), W(t), U(t))$ be an arbitrary solution of system (1.3). Differentiating (2.1) with respect to $t$, along this solution, calculations give that

EÜFBED - Fen Bilimleri Enstitüsü Dergisi Cilt-Sayı: 8-2 Yıl: 2015 248-258 


$$
\begin{aligned}
\dot{V}= & \frac{d}{d t} V(X, Y, Z, W, U) \\
= & \langle W, W\rangle+\langle Y, \theta(X, Y, Z, W, U) W\rangle+\langle Y, F(Y) Z\rangle \\
& +\langle Y, G(X, Y, Z, W, U) Y\rangle+\langle Y, H(X) Y\rangle-\frac{d}{d t} \int_{0}^{1}\langle\sigma F(\sigma Y) Y, Y\rangle d \sigma \\
& -\frac{d}{d t} \int_{0}^{1}\langle H(\sigma X), X\rangle d \sigma
\end{aligned}
$$

Now, we recall that

$$
\frac{d}{d t} \int_{0}^{1}\langle\sigma F(\sigma Y) Y, Y\rangle d \sigma=\left.\sigma^{2}\langle F(\sigma Y) Z, Y\rangle\right|_{0} ^{1}=\langle F(Y) Z, Y\rangle,
$$

and

$\frac{d}{d t} \int_{0}^{1}\langle H(\sigma X), X\rangle d \sigma=\left.\sigma\langle H(\sigma X), Y\rangle\right|_{0} ^{1}=\langle H(X), Y\rangle$.

Substituting (2.5) and (2.6) into (2.4) and taking into account the conditions of the Theorem 2.1, we obtain

$$
\begin{aligned}
& \dot{V}=\langle W, W\rangle+\langle Y, \theta(X, Y, Z, W, U) W\rangle+\langle Y, G(X, Y, Z, W, U) Y\rangle \\
&=\left\|W+\frac{1}{2} \theta(X, Y, Z, W, U) Y\right\|^{2}-\frac{1}{4}\langle\theta(X, Y, Z, W, U) Y, \theta(X, Y, Z, W, U) Y\rangle \\
&+\langle Y, G(X, Y, Z, W, U) Y\rangle \\
& \geq\langle Y, G(X, Y, Z, W, U) Y\rangle-\frac{1}{4}\langle\theta(X, Y, Z, W, U) Y, \theta(X, Y, Z, W, U) Y\rangle>0 .
\end{aligned}
$$


Karta

Taking into account the conditions of the Theorem 2.1, we deduce from (2.6) that $\dot{V}(t) \geq 0$ for all $t \geq 0$, that is, $\dot{V}$ is positive semidefinite. This shows that $\left(K_{2}\right)$ feature of (Krasovskii 1955) is satisfied. Furthermore, $\dot{V}=0(t \geq 0)$ necessarily implies that $Y=0$ for all $t \geq 0$, and also $X=\xi$ (a constant vector) $, Z=\dot{Y}=0, W=\ddot{Y}=0, \dot{W}=\ddot{Y}=0$, for all $t \geq 0$.If these statements are written in (1.3), we can clearly see that it is $H(\xi)=0$, which necessarily shows that $\xi=0$ because $H(0)=0$ and $H(X) \neq 0$ if $X \neq 0$.Thus, it follows that

$X=Y=Z=W=U=0$ for all $t \geq 0$.

If this happens, it shows $\left(K_{3}\right)$ feature of (Krasovskii 1955) is satisfied. As a result, taking into account the conditions of Theorem 2.1, the function $V$ ensures the entire the criteria of (Krasovskii 1955). Thus, the fundamental properties of the function $V(X, Y, Z, W, U)$, which were proved above, imply that the zero solution of system (1.3) is unstable. The system (1.3) is equivalent to the differential equation (1.2). Therefore, the proof of Theorem (2.1) is complete.

Now, we give an example for Theorem (2.1).

\section{Example:}

As special cases of system (1.3), if we take for $n=2$,

$$
\begin{aligned}
& A=\left[\begin{array}{ll}
2 & 1 \\
1 & 2
\end{array}\right], \Theta=\left[\begin{array}{cc}
2 & -\frac{2}{1+x_{1}^{2}+y_{1}^{2}} \\
-\frac{2}{1+x_{1}{ }^{2}+y_{1}^{2}} & 2
\end{array}\right], \\
& G=\left[\begin{array}{cc}
x_{1}^{2}+y_{1}^{2}+2 & 1 \\
1 & x_{1}^{2}+y_{1}^{2}+2
\end{array}\right]
\end{aligned}
$$

Then, respectively, we have

$$
\begin{aligned}
& \lambda_{1}(A)=1, \quad \lambda_{2}(A)=3, \\
& \lambda_{1}(\Theta)=\frac{2 x_{1}^{2}+2 y_{1}^{2}}{1+x_{1}^{2}+y_{1}^{2}}, \quad \lambda_{2}(\Theta)=\frac{4+2 x_{1}^{2}+2 y_{1}^{2}}{1+x_{1}^{2}+y_{1}^{2}},
\end{aligned}
$$

EÜFBED - Fen Bilimleri Enstitüsü Dergisi Cilt-Sayı: 8-2 Yıl: 2015 248-258 
A New Instability Result on The Solutions of Nonlinear Vector

$\lambda_{1}(G)=x_{1}^{2}+\mathrm{y}_{1}^{2}+1, \quad \lambda_{2}(G)=x_{1}^{2}+y_{1}^{2}+3$.

Hence

$\lambda_{i}(A)>1=a_{1},(i=1,2)$

and

$$
\begin{aligned}
\lambda_{1}(G)-\frac{1}{4} \lambda_{1}(\Theta)^{2} & =x_{1}^{2}+y_{1}^{2}+1-\frac{1}{4} \frac{\left(2 x_{1}^{2}+2 y_{1}^{2}\right)^{2}}{\left(1+x_{1}^{2}+y_{1}^{2}\right)^{2}} \\
& =\frac{4\left(x_{1}^{2}+y_{1}^{2}+1\right)\left(1+x_{1}^{2}+y_{1}^{2}\right)^{2}-\left(2 x_{1}^{2}+2 y_{1}^{2}\right)^{2}}{4\left(1+x_{1}^{2}+y_{1}^{2}\right)^{2}}>0
\end{aligned}
$$

$\lambda_{2}(G)-\frac{1}{4} \lambda_{2}(\Theta)=x_{1}^{2}+y_{1}^{2}+3-\frac{1}{4} \frac{\left(4+2 x_{1}^{2}+2 y_{1}^{2}\right)^{2}}{\left(1+x_{1}^{2}+y_{1}^{2}\right)^{2}}$

$$
=\frac{4\left(x_{1}^{2}+y_{1}^{2}+3\right)\left(1+x_{1}^{2}+y_{1}^{2}\right)^{2}-\left(4+2 x_{1}^{2}+2 y_{1}^{2}\right)^{2}}{4\left(1+x_{1}^{2}+y_{1}^{2}\right)^{2}}>0
$$

Clearly, these last two expressions imply that

$\lambda_{i}(G(X, Y, Z, W, U))-\frac{1}{4}\left(\lambda_{i}(\Theta(X, Y, Z, W, U))\right)^{2}>0, \quad(i=1,2)$

Thus, it is shown that all the assumptions of theorem (2.1) are provided.

\section{REFERENCES}

Ezeilo, J. O. C., 1978. Instability theorems for certain fifth-order differential equations. Math. Proc. Cambridge Philos. Soc., 84(2), 343350 .

Ezeilo, J. O. C., 1979. A further instability theorem for a certain fifthorder differential equation. Math. Proc. Cambridge Philos. Soc., 86(3), 491-493.

Tiryaki, A., 1987. Extension of an instability theorem for a certain fifth order differential equation. National Mathematics Symposium, J.

EÜFBED - Fen Bilimleri Enstitüsü Dergisi Cilt-Sayı: 8-2 Yıl: 2015 248-258 
Karta

Karadeniz Tech. Univ. Fac.Arts Sci. Ser. Math. Phys., 11, Trabzon, 225227,

Li, W. J., Yu, Y. H., 1990. Instabilitiy theorems for some fourth-order and fifth-order differential equations. (Chinese) J. Xinjiang Univ. Natur. Sci., 7(2), 7-10.

Li, W., Duan, K., 2000. Instability theorems for some nonlinear differential systems of fifth order. (Chinese) J. Xinjiang Univ. Natur. Sci., 17(3), 1-5.

Sadek, A.I., 2003. Instability results for certain systems of fourth and fifth order differential equations. Appl . Math. Comput., 145(2-3), 541-549.

Tunç, C., 2004. On the instability of solutions of certain nonlinear vector differential equations of fifth order. Panamer. Math. J., 14(4), 2530.

Tunç, C., 2005. An instability result for a certain non-autonomous vector differential equation of fifth-order. Panamer. Math. J., 15(3), 5158.

Tunç, C., Şevli, H., 2005. On the instability of solutions of certain fifth order nonlinear differential equations. Mem. Differential Equations Math. Phys., 35, 147-156.

Tunç, C., 2008. Further results on the instability of solutions of certain nonlinear vector differential equations of fifth order. Appl. Math. Inf. Sci ., 2(1) , 51-60.

Tunç, C., Karta, M., 2008. A new instability result to nonlinear vector differential equations of fifth order. Discrete Dynamics in Nature and Society., 2008, doi:10.1155/2008/971534.

Tunç, C., 2004. An instability theorem for a certain vector differential equation of the fourth order. Journal of Inequalities in Pure and Applied Mathematics.,5(1),1-5.

Tunç, C., 2007. Some instability results on certain third order nonlinear vector differential equations Bulletin of the Institute of Mathematics Academia Sinica(new series).2(1), 109-122.

EÜFBED - Fen Bilimleri Enstitüsü Dergisi Cilt-Sayı: 8-2 Yıl: 2015 248-258 
A New Instability Result on The Solutions of Nonlinear Vector Tunç,C., Erdoğan,F., 2007. On the instability of solutions of certain non- autonomous vector differential equations of fifth order. Sut J.Math. 43(1),35-38.

Tunç, C., 2008. Further results on the instability of solutions of certain nonlinear vector differential equations of fifth order. Appl. Math.Inf. Sci. 2(1), 51-60.

Tunç, C., 2011. A instability theorem for a certain fifth order delay differential equation, Filomat 25(3), 145-151.

Tunç, C., 2011. On the instability of solutions of some fifth order nonlinear delay differential equations. Appl. Math. Inf. Sci.5(1), 112121.

Tunç, C., 2012. Instability of non linear functional differential equations of fifth order. ITB J.Sci. 44(3), 239-249.

Tunç, C., 2013. Instability to nonlinear vector differential equations of fifth order with constant delay.J.Math.Appl.36,121-130.

Tunç, C., 2013.Instability of a fifth ordernon linear vector delay differential equation with multiple deviating arguments. U.P.B.Sci. Bull., Series A.76(1), 155-162.

Krasovskii, N. N., 1955. On conditions of inversion of A.M. Lyapunov's theorems on instability for stationary systems of differential equations. (Russian) Doklady Akademii Nauk SSSR., 101,1720.

Lyapunov, A. M., 1966. Stability of Motion. Academic Press, New York-London, 203p.

Horn, R. A., Johnson, C.R., 1994. Topics in Matrix Analysis. Cambridge University Press, Cambridge, UK. 